\title{
Wireless Water Pump Control for Farming
}

\section{Laxmi Goswami}

\begin{abstract}
The agriculture is one of the biggest industry of India, it covers almost $60 \%$ of all industries. Almost all the industries are dependent of agriculture directly or indirectly. So, there is a need for improvement in agriculture sector, in this paper a technology is discussed which will remove the most of the issues related to irrigation system of farm. A system is designed for wireless starting and stop the water pump of farm via using a microcontroller for controlling system, a gsm module which is responsible for communication purpose, a relay for improving the safety of system, 9 Volt power supply for powering control system and a cell phone for sending and receiving data from microcontroller.
\end{abstract}

Keywords: agriculture, industry, irrigation, wireless, turn on/off, microcontroller, GSM, relay, cell phone, power supply

\section{INTRODUCTION}

In past decades mobile phone technology is improved exponentially it is the biggest communication mode in current era[1]. The cell phone made communication very easy and everyone is easily accessible to everyone. This all communication is happen by using GSM module which is responsible for all the calls, SMS, and internet communication. The GSM module works on $900 \mathrm{MHz}$ or $1800 \mathrm{MHz}$ frequency band only[2]. The GSM module requires a SIM (Subscribers Identity Module) for communicating with others. In this project we used this technology for communicating with the user. The system is designed for starting/stopping the water pump situated on farm wirelessly using cell phone. The system comprises an Arduino Uno which is connected with a GSM module and a SIM is placed inside the module, a relay for restricting the flow of current in the system if any abnormality is detect and relay also works as switch in this project for turning on/off water pump of the system.

\section{TECHNOLOGIES USED}

Controlled Power Supply: The controlled power supply is a unit which is specifically designed for converting 220Volt AC into 9 Volt DC power. This process includes a Step down transformer which step downs the 220 Volt AC power into 12 Volt DC, after this the AC power is fed to $\mathrm{H}$-Bridge rectifier for converting 9 Volt $\mathrm{AC}$ to 9 Volt $\mathrm{DC}$ power which is moved through a filtering circuit for removing any unwanted fluctuation of power which might damage the unit[3][4][5].

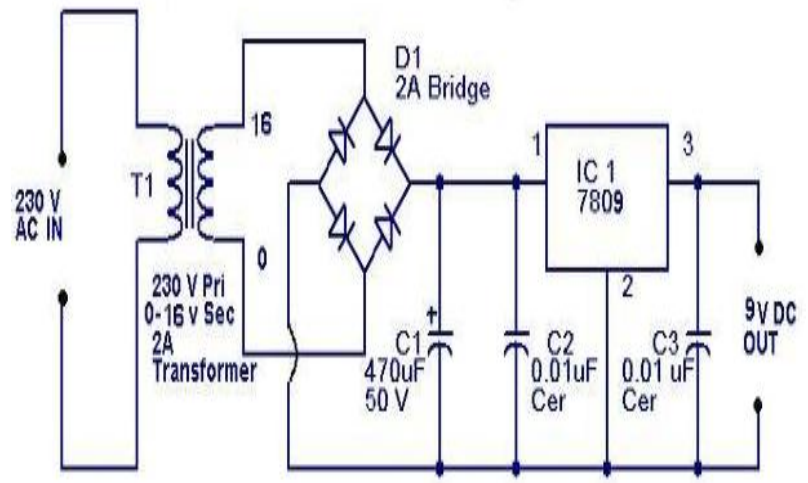

Figure 1: Circuit Diagram of 9 Volt power supply unit

Arduino Uno: The Arduino Uno is a microcontroller which have ability to control electrical and electronics components by a control signal, the Arduino Uno have an Atmega628P IC which is programmable by using a software known as Arduino IDE which uses $\mathrm{C}$ and $\mathrm{C}++$ used as programming languages. The Arduino Uno have multiple pins it includes digitalwrite pin, analogwrite pin and many more. The Arduino is capable for taking input from sensors and can act accordingly[6][7].

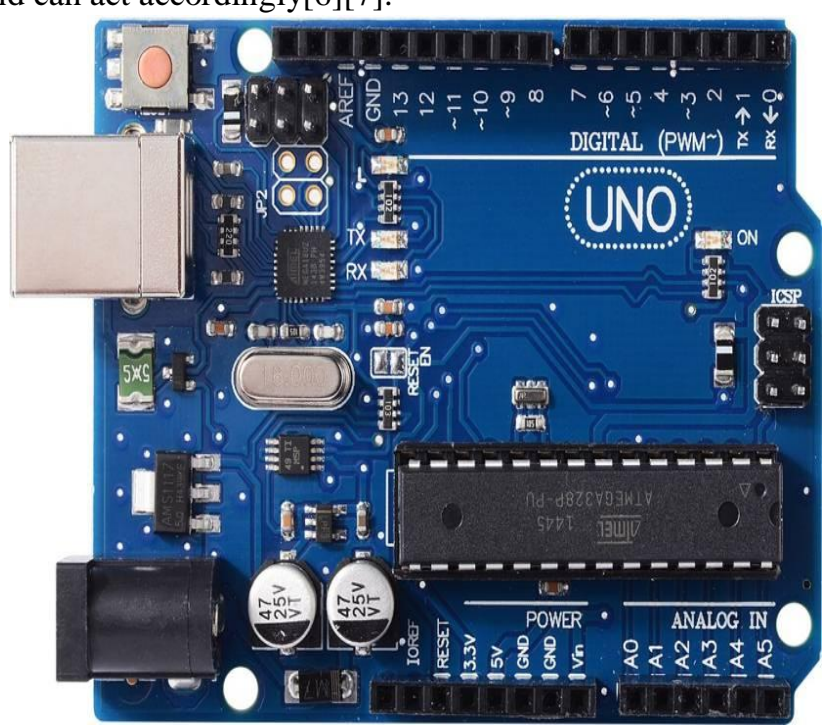

Figure 2: Arduino Uno

GSM module: The GSM module is an electronic device which is responsible for the working of SIM which is placed inside the module for send and receiving call i.e. the GSM module is pathway for wireless communication[8]. 


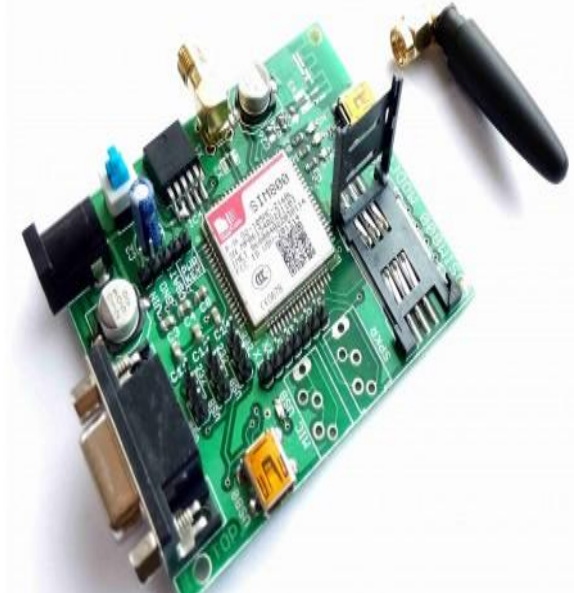

Figure 3: GSM module

Mechanical Relay: The mechanical relay is an electromechanical device which works as a switch. The mechanical relay can be controlled by a microcontroller by giving 5 Volt as input. The mechanical relay have a coil and a plate which completes the circuit. When a current passes through the coil is generates electromagnetic field which attracts the plate towards coil and when the flow of current stops the coil releases. By using this mechanism the relay performs switching operation[9].

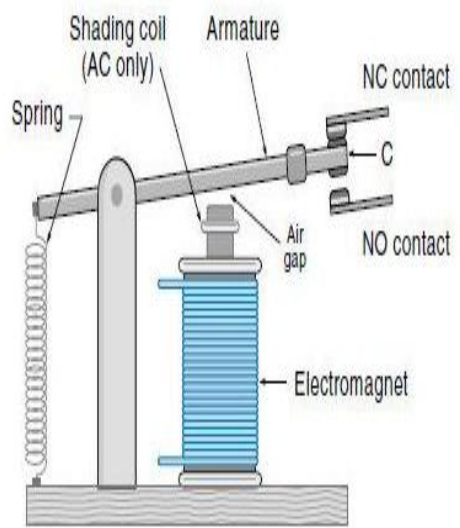

(a)

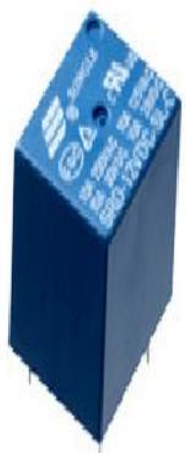

(b)
Figure 4: (a) Schematic Representation of mechanical relay (b) Mechanical Relay

Water Pump: Water pump is device which is used for pumping water from one location to another by using electricity. The pump comprises a motor which is connected to plurality of fans which helps to pump water[10].

\section{PROPOSED MODEL}

The proposed model comprises a water pump controlling unit, the system comprises a microcontroller for performing arithmetic and logical operation, a GSM module is connected with microcontroller and a SIM card is placed inside the GSM module for communication purpose, a relay is connected with microcontroller and main power supply which is responsible for powering the water pump and a 9 Volt power supply which powers motor controlling system.

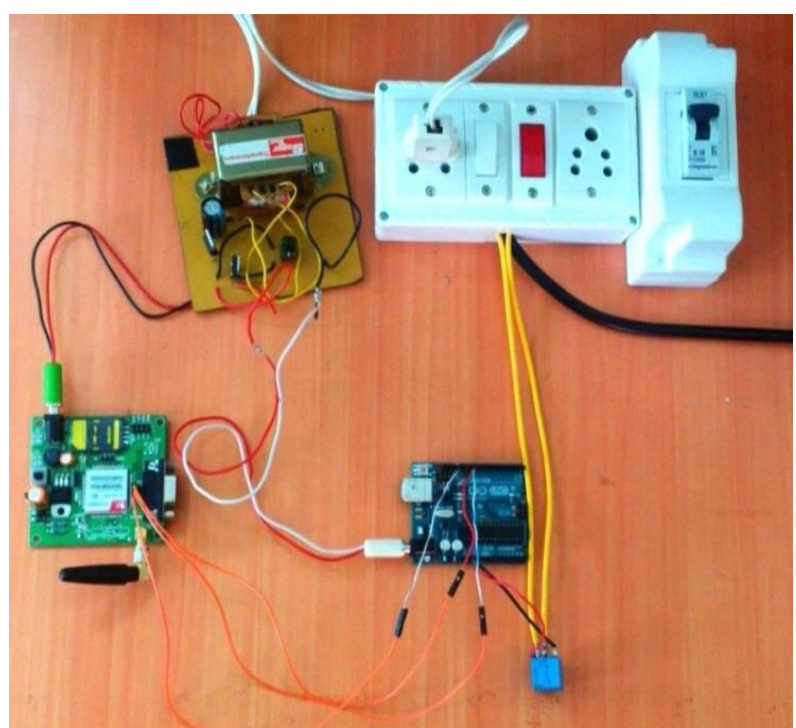

Figure 5: Prototype 1

\section{PROPOSED MODEL WORKING}

When user send a signal (Call/SMS) via cell phone to the controlling via GSM module, the microcontroller process the signal and start/stop the water pump according to received signal. And whenever the microcontroller detects any abnormality it send out a signal to user by using GSM module and SIM for alerting the user regarding the abnormality in operation of motor and restricts the flow of current to water pump by using a mechanical relay which is connected with the controller and main power supply. The alert signal is a SMS which is generated by microcontroller.

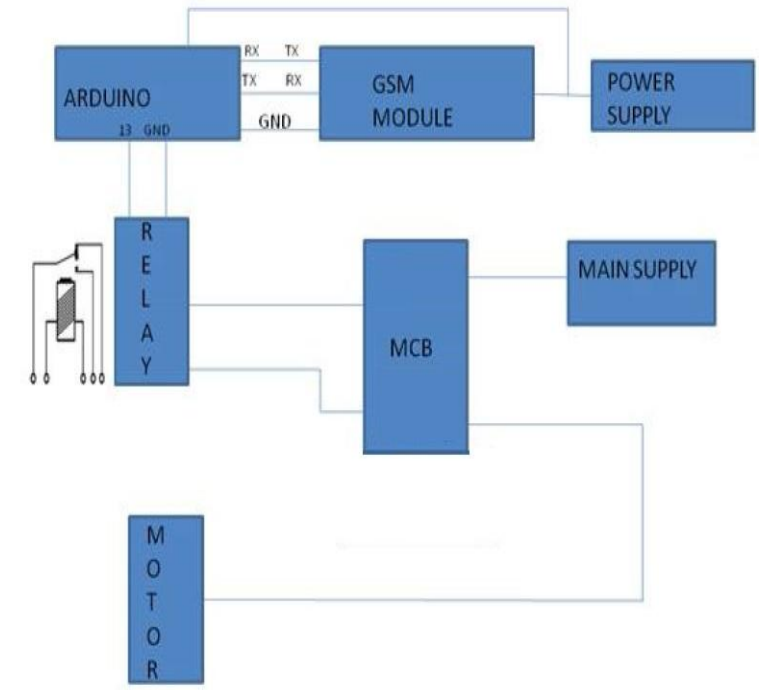

Figure 6: Block Diagram of working of control system

\section{RESULT}

The system is tested for 500 times and worded each time accurately in real life environment. A 1.5 HP water pump is connected with the control system and operated for 30 days on regular basis, the system responded each time a user sends operating instruction to the control unit and worked optimally.

Published By:

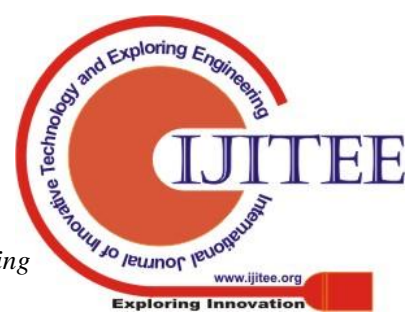




\section{CONCLUSION}

The system worked as designed and planned without any malfunctions, the designed prototype worked 100\% accurately. The system is used for irrigation purpose for 1 acre field and used for filling water storage unit of a house. In future sensors will be installed in system for measuring water level of tank and automatically starting the water pump and moisture sensors will be installed in fields and control unit will take feedback from these sensors and automatically will start the water pump, this will improve the production from farm.

\section{REFERENCE}

1. R. Ling, "Mobile Communication," in International Encyclopedia of the Social \& Behavioral Sciences. Second Edition, 2015.

2. J. Rigelsford, "GSM Networks: Protocols, Terminology and Implementation," Sens. Rev., 2014.

3. J. J. Shea, "Power Transformers-Principles and Applications [Book Review]," IEEE Electr. Insul. Mag., 2003.

4. Y. S. Lee and M. H. L. Chow, "Diode rectifiers," in Power Electronics Handbook, 2011.

5. J. P. Johnson, "DC-DC converters," in Handbook of Automotive Power Electronics and Motor Drives, 2017.

6. D. R. Tobergte and S. Curtis, "Arduino Uno," J. Chem. Inf. Model., 2013.

7. D. Wheat and D. Wheat, "Arduino Software," in Arduino Internals, 2012.

8. J. C. Fagan and J. A. Keach, "Technical specifications," in Web Project Management for Academic Libraries, 2014.

9. G. Nicoll and M. J. Boss, "Relays," in Electrical Safety: Systems, Sustainability, and Stewardship, 2014.

10. P. Yang, "Wires on water," Nature, 2003. 